\title{
A Novel Adaptive Speed Observer Using Neural Network and Sliding-Mode for SPIM Drives
}

\author{
Ngoc Thuy Pham \\ Dept. of Electrical Engineering Technology, \\ Industrial University of Ho Chi Minh City \\ Vietnam
}

\begin{abstract}
In this paper, a novel Stator Current Based Model Reference Adaptive System (SC_MRAS) speed estimation scheme using neural network (NN) and Sliding Mode (SM) is proposed to improve the performance of the MRAS speed observer for high-performance Six Phases Induction Motor (SPIM) drives, especially at low and zero speed region, where the poor performance of observers is still always a large challenge. In this novel SC_MRAS scheme, a two-layer linear $\mathrm{NN}$, which has been trained online by means of the Total Least Squares (TLS) algorithm, is used as an adaptive model to estimate the stator current and this model is employed in prediction mode. These novel proposed can ensure that the whole drive system achieves faster satisfactory torque and speed control and strong robustness, the observer operate better accuracy and stability both in transient and steady-state operation. Especially, in this proposed observer, the rotor flux, which is needed for the stator current estimation of the adaptive model and providing to the controller, is identified based on adaptive SM technique. The improvement of Rotor Flux Estimation for SC_MRAS-Based Sensorless SPIM Drives help to eliminate the disadvantages in SC_MRAS based observer such as stator resistance sensitivity, and flux open loop integration which may cause dc drift and initial condition problems or instability in the regenerating mode of operation, therefore, enhancing the rotor flux estimation, speed estimation and control accuracy at very low and zero stator frequency operation help improve the overall observer and drive system performance. The indirect field oriented control (IFOC) for speed control of a sensorless SPIM drive using the proposed observer is built by MATLAB/ Simulink. The simulation results are presented under sensorless speed control performance to validate the effectiveness of the proposed estimation and control algorithms.
\end{abstract}

Key-Words: Neural network, Sensorless vector control, Six phase induction motor drive, MRAS observer.

\section{INTRODUCTION}

$I^{2}$ $\mathrm{N}$ the past decades, multiphase motor drives have been proposed for applications [1-3] due to its advantages are such as: decrease the single switches current stress instead of adopting parallel techniques, low electromagnetic torque pulsations, DC link current harmonics, overall system reliability and better power distribution per phase improve the overall system reliability [3]. Among the different control solutions for SPIM drives, one of the most interesting and extensively discussed in the literature is SPIM having two sets of three-phase windings spatially shifted by 30 electrical degrees. Neutral points of the two windings can be isolated or connected. The major reason for selecting the asymmetrical six-phase winding instead of the true sixphase winding $\left(60^{\circ}\right.$ displacement between any two consecutive phases) was the elimination of the sixth harmonic from the torque [3], which is important in sixphase IM drives using voltage source inverter (VSI) with six-step operation.

In order to regulate the SPIM in highperformance applications several control techniques have been developed being the field oriented control method [1] one of the most popular techniques. The correct knowledge of rotor speed information for field orientation is required. Moreover, the precise speed signal for closed-loop control is needed; therefore, speed encoders are essential to be mounted on the rotor shaft for position and speed information [4]. However, the encoder causes extra cost, larger size, and extra wiring of IM drives and limits their applications in a relatively harsh environment. In recent years, the development of sensorless IM drives without encoders or sensors have becoming more and more popular due to their advantages of minimizing production costs and developing a reliable and robust control system. Sensorless techniques are employed in hostile environments and also for emergency operations in safety-critical applications in case of failure of the sensor. They usually are divided into two categories, the fundamental model based observers and anisotropies model based observers. Model-based estimation strategies include open-loop observers [5], sliding-mode observers [6], Extended Kalman Filter [7], Backstepping [8], model reference adaptive systems (MRAS) [9] and artificial intelligence (AI) [10]. Recent research also used predictive current control for sensorless IM drives [11]. Sensorless drives have been successfully applied in medium and high speed regions [12], [13], but low and zero speed operation is still a large challenge. In order to overcome these problems a high frequency voltage or current carrier were injected, needed to excite the saliency itself [14]. This method works well at low and near zero speed region. However, their major disadvantages are computational complexity, the need of external hardware for signal injection and the adverse effect of injecting signal on the machine performance. Due to its simplicity and ease of implementation the model based methods and especially MRAS based methods are, until now, the most widely used. The main 
problems associated with the low speed operation of model-based sensorless drives are related to machine parameter sensitivity, stator voltage and current acquisition, and flux pure integration problems [15-18].

Numerous MRAS have been proposed. Among them, the rotor flux MRAS first introduced by Schauder [19], Flux Backstepping Observer [20], both suffer from DC drift problems associated with pure integration and sensitivity to stator resistance variation, especially in the low speed region. In order to improve the performance of observer overcome the effect by sensitivity to stator resistance variation, online adaptation of the stator resistance [21], the pure integration problems, Extended Kalman Filter (EKF), a modified torque based on MRAS schemes have proposed in [19], [20], respectively. Although [22] , [23] have shown that these approaches significantly improve the performance of the RF-MRAS at low speed, these scheme remain the effected by the sensitivity to parameter variations. An improved rotor flux estimation to eliminate the pure integration problems and the effect of sensitivity to parameter variations for a Torque MRAS is proposed in [24]. Simulation and experimental results are shown the sensorless control drive operating at low and zero speeds, with both motoring and regenerative operations considered. The performance of the observer in low speed regenerating region and the performance of the transient and steady state were significantly improved at very low and zero rotor speeds. Analysis of the effect of parameter variation on the scheme performance has shown improved robustness against stator and rotor resistance variation over a wider range of load torques compared to results previously published for the conventional scheme. However, the estimated error increase at very low (3.14 rad/s) and zero speed range is recorded. The performance of the speed estimation in low speed regenerating region and the performance of the transient and steady state is not really satisfied.

Another approach, the stator current MRAS scheme has been introduced in [25-27]. [26] presents a stator current based MRAS speed observer using $\mathrm{NN}$, which is an evolution of [25]. In this proposed scheme, to avoid the effect of a pure integrator and reduce influence of motor parameter variations, the measured stator current components are used as the reference model. The adaptive model of the proposed observer in [26] uses a two-layer NN with a BPN algorithm to estimate the rotor speed, an off-line trained multilayer feed-forward neural network is proposed as a rotor flux observer. The simulation and experimental results have proven that the significantly improvement operation performance in low and zero speed ranges, the lowest speed limit $25 \mathrm{rpm}(2.6$ $\mathrm{rad} / \mathrm{s}$ ) was reported. The results in [20] also demonstrate that the proposed observer can handle the parameter variation problem with a good level of robustness, sensorless performance with a $50 \%$ variation in resistances at low speed, 25\% load. Although [26] can overcome the main problems associated with the low zero and speed operation, however, due to [26] the use of the nonlinear BPN algorithm to training a neural network causes some problem as local minima, paralysis of the neural network, need of two heuristically chosen parameters, initialization problems, and convergence problems. These make the performance of observer in [26] is not really as expected. The speed estimation error and oscillation phenomenon at low and zero increase. Other side, the adaptive model in [26] is used in simulation mode, which means that its outputs are fed back recursively, this also make reduce the accuracy and stability of the responses of observer. Finally, the use of two networks: the first is online trained for stator current estimation and the second is off-line trained for rotor flux estimation will make increase the complexity and computational burden require high about hardware and time handle the data. This impose a large disadvantage of MRAS [26].

In this paper, a SC MRAS based observer using NN and $\mathrm{SM}$ is proposed for improving the performance of the sensorless vector control SPIM drives, especially in low and zero speed ranges. the new points are developed in this SC_MRAS scheme are, first: Adaptive model uses a two layer linear neural network, which is trained online by a linear TLS algorithm, this algorithm requires the less computation effort and overcome some drawbacks, which cause by its inherent nonlinearity as in literature published before [26]. The other side, the TLS neuron has been employed because it permits to take into consideration also the uncertainty of the elements of the data matrix, which in real world applications are due to noisy measurements and incorrect estimation, these problems is able to yet to be sovled thoroughly more OLS algorithm in [27], Second: the adaptive model based on $\mathrm{NN}$ is implemented in the prediction mode with no feedback loops between the output of the neural network and its input. This neural model is also used as a predictor with no feedback loops between the output of the neural network and its input. This improvement ensures the proposed observer operate better accuracy and stability, and especially, third: , an rotor flux identifier, which is needed for the stator current estimation of the adaptive model and controller, is proposed based on SM. The gains are designed based on stability conditions of Lyapunov theory. This solution improves the rotor flux estimation accuracy, and consequently, the speed estimation accuracy at very low stator frequency operation. Finally, the modified Euler integration has been used in the adaptive model to solve the instability problems due to the discretization of the rotor equations of the machine enhance the performance of observer.

The indirect field oriented control (IFOC) for speed control of a sensorless SPIM drive using the proposed estimation algorithms is built by MATLAB/ Simulink. The theoretical analysis is validated by simulation tests of the sensorless SPIM drive system under different operating conditions. Simulation results are given to compare the performance of the proposed observer with recent proposed observer. The comparison data have proven that the proposed NN_SM_SC_MRAS observer are quicker convergence in speed estimation, better dynamic performances; lower estimation errors both in transient and steady-state operation. The terms of 
accuracy of the NN_SM_SC_MRAS observers is quite high and it is robustness against motor parameter variations. The paper is organized into five sections. In Section 2, the basic theory of the model of the SPIM and the SPIM drive are presented. Section 3 introduces the proposed NN_SM_SC_MRAS observer. Simulation and discuss are presented in Section 4. Finally, the concluding is provided in Section 5.

\section{MODEL VECTOR CONTROL OF SPIM DRIVE}

The system under study consists of an SPIM fed by a six-phase Voltage Source Inverter (VSI) and a DC link. A detailed scheme of the drive is provided in Fig.1. By applying the Vector Space Decomposition (VSD) technique introduced in [18], the original sixdimensional space of the machine is transformed into three two dimensional orthogonal subspaces in the stationary reference frame $(\mathrm{D}-\mathrm{Q}),(\mathrm{x}-\mathrm{y})$ and $(\mathrm{zl}-\mathrm{z} 2)$. This transformation is obtained by means of $6 \times 6$ transformation matrix:

$$
T_{6}=\left[\begin{array}{cccccc}
1 & \frac{\sqrt{3}}{2} & -\frac{1}{2} & -\frac{\sqrt{3}}{2} & -\frac{1}{2} & 0 \\
0 & \frac{1}{2} & \frac{\sqrt{3}}{2} & \frac{1}{2} & -\frac{\sqrt{3}}{2} & -1 \\
1 & -\frac{\sqrt{3}}{2} & -\frac{1}{2} & \frac{\sqrt{3}}{2} & -\frac{1}{2} & 0 \\
0 & \frac{1}{2} & -\frac{\sqrt{3}}{2} & \frac{1}{2} & \frac{\sqrt{3}}{2} & -1 \\
1 & 0 & 1 & 0 & 1 & 0 \\
0 & 1 & 0 & 1 & 0 & 1
\end{array}\right]
$$

In order to develop SPIM model for control purposes, some basic assumptions should be made. Hence, the windings are assumed to be sinusoidally distributed, the magnetic saturation, the mutual leakage inductances, and the core losses are neglected. The electrical matrix equations in the stationary reference frame for the stator and the rotor may be written as

$$
\begin{aligned}
{\left[V_{s}\right] } & =\left[R_{s}\right]\left[I_{s}\right]+P\left(\left[L_{s}\right]\left[I_{s}\right]+\left[L_{m}\right]\left[I_{r}\right]\right) \\
0 & =\left[R_{r}\right]\left[I_{r}\right]+P\left(\left[L_{r}\right]\left[I_{r}\right]+\left[L_{m}\right]\left[I_{s}\right]\right)
\end{aligned}
$$

where: $[\mathrm{V}],[\mathrm{I}],[\mathrm{R}],[\mathrm{L}]$ and $[\mathrm{Lm}]$ are voltage, current, resistant, self and mutual inductance vectors, respectively. $\mathrm{P}$ is differential operator. Subscript $\mathrm{r}$ and $\mathrm{s}$ related to the rotor and stator resistance respectively. Since the rotor is squirrel cage, $[\mathrm{Vr}]$ is equal to zero. The electromechanical energy conversion only takes place in the DQ subsystem:

$$
\left[\begin{array}{c}
V_{s D} \\
V_{s Q} \\
0 \\
0
\end{array}\right]=\left[\begin{array}{cccc}
R_{s}+P L_{s} & 0 & P L_{m} & 0 \\
0 & R_{s}+P L_{s} & 0 & P L_{m} \\
P L_{m} & \omega_{r} L_{m} & R_{r}+P L_{r} & \omega L_{r} \\
-\omega L_{m} & P L_{m} & -\omega_{r} & R_{r}+P L_{r}
\end{array}\right]\left[\begin{array}{c}
I_{s q} \\
I_{r \beta} \\
I_{r \alpha}
\end{array}\right]
$$

As these equations implies, the electromechanical conversion, only takes place in the D-Q subspace and the other subspaces just produce losses. Therefore, the control is based on determining the applied voltage in the $\alpha \beta$ reference frame. With this transformation, the 6PIM control technique is similar to the classical three phase IM FOC. The control for the motor in the stationary reference frame is difficult, even for a three phase IM, so the transformation of SPIM model in a dq rotating reference frame to obtain currents with dc components[1] của 1 is necessary, a transformation matrix must be used to represent the stationary reference fame $(\alpha-\beta)$ in the dynamic reference $(d-q)$. This matrix is given:

$$
T_{d q}=\left[\begin{array}{cc}
\cos \left(\delta_{r}\right) & -\sin \left(\delta_{r}\right) \\
\sin \left(\delta_{r}\right) & \cos \left(\delta_{r}\right)
\end{array}\right]
$$

where $\delta r$ is the rotor angular position referred to the stator as shown in Fig. 1.

The field oriented control (FOC) is the most used strategy in the industrial field. Its objective is to improve the static and dynamic behavior of asynchronous machine unlike the scalar control. It allows decoupling the electromagnetic quantities in order to make the control similar to DC machine. The principle of the FOC is to align the $\mathrm{d}$ axis of the rotating frame $(\mathrm{Dq}(\mathrm{d}-\mathrm{q}))$ with the desired flux as shown in Fig. 1. Therefore, the flux will be controlled by the direct component of the stator current (isd) and the torque by the quadratic component (isq). In this case we obtain: $\psi_{r q}=0 ; \quad \psi_{r d}=\psi_{r d}$

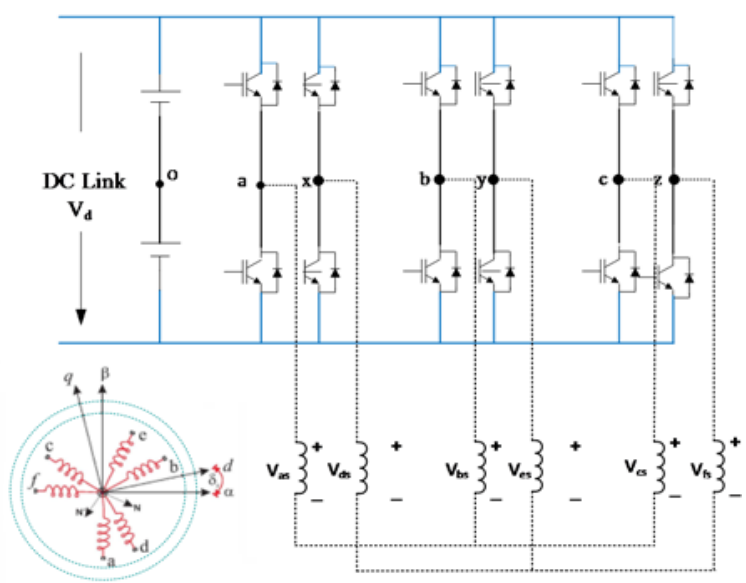

Fig. 1 A general scheme of an SPIM drive 
Using Eqs. (1) and (4), the new model motor dynamics is described by the following space vector differential equations:

$$
\left\{\begin{array}{l}
\frac{d \omega}{d t}=\frac{3}{2} n_{p} \frac{\delta \sigma L_{s}}{J}\left(\psi_{r d} i_{s Q}\right)-\frac{T_{L}}{J}-B \omega \\
\frac{d \psi_{r d}}{d t}=\frac{L_{m}}{\tau_{r}} i_{s D}-\frac{1}{\tau_{r}} \psi_{r d} \\
L_{s} \frac{d i_{s D}}{d t}=-a i_{s D}+L_{s} \omega_{s} i_{s Q}+b R_{r} \psi_{r d}+c u_{s D} \\
L_{s} \frac{d i_{s Q}}{d t}=-a i_{s Q}+L_{s} \omega_{s} i_{s D}+b_{r} \omega_{r} \psi_{r d}+c u_{s Q}
\end{array}\right.
$$

\section{NN_SM_SC_MRAS SPEED OBSERVER}

\section{A. NNSM_SC_MRAS speed Observer}

In this scheme, the measured stator current components are also used as the reference model of the MRAS observer to avoid the use of a pure integrator and reduce influence of motor parameter variation as in [25-26]. The adaptive model is a two-layer linear NN to estimate the stator current has been trained online by means of a leastsquares (LS) algorithm. This adaptive model is described by the combined voltage- and current models in the stator reference frame (6)

$$
\begin{aligned}
& T_{n} \frac{\mathrm{d} \hat{\mathbf{i}}_{s D}}{d t}=\frac{1}{x_{s} \sigma}\left[\mathrm{u}_{r D}-r_{s} i_{s D}\right. \\
& \left.-\frac{x_{m}}{x_{r}}\left(r_{r} \frac{x_{m}}{x_{r}} i_{S D}-\frac{r_{r}}{x_{r}} \Psi_{r D}-\omega \Psi_{r Q}\right)\right] \\
& T_{n} \frac{\mathrm{d} \hat{\mathbf{i}}_{s Q}}{d t}=\frac{1}{x_{s} \sigma} \mathrm{u}_{r Q}-r_{s} i_{s Q}- \\
& \frac{x_{m}}{x_{r}}\left(r_{r} \frac{x_{m}}{x_{r}} i_{s Q}-\frac{r_{r}}{x_{r}} \Psi_{r Q}+\omega \Psi_{r D}\right) \\
& \hat{\mathrm{l}}_{\mathrm{sD}}(\mathrm{k})=\mathrm{w}_{1} \hat{\mathrm{l}}_{\mathrm{sD}}(\mathrm{k}-1)+\mathrm{w}_{2} \mathrm{v}_{\mathrm{sD}}(\mathrm{k}-1)+\mathrm{w}_{3} \widehat{\Psi}_{\mathrm{rD}}(\mathrm{k}-1)+\mathrm{w}_{4} \widehat{\Psi}_{\mathrm{rQ}}(\mathrm{k}-1) \\
& \hat{\mathrm{s}}_{\mathrm{SQ}}(\mathrm{k})=\mathrm{w}_{1} \hat{\mathrm{s}}_{\mathrm{sQ}}(\mathrm{k}-1)+\mathrm{w}_{2} \mathrm{v}_{\mathrm{SQ}}(\mathrm{k}-1)+\mathrm{w}_{3} \widehat{\mathrm{T}}_{\mathrm{rQ}}(\mathrm{k}-1)-\mathrm{w}_{4} \widehat{\mathrm{T}}_{\mathrm{rD}}(\mathrm{k}-1) \\
& \mathrm{e}^{\mathrm{AT}_{\mathrm{s}}}=\mathrm{I}+\frac{\mathrm{AT}_{\mathrm{s}}}{1 !}+\frac{\mathrm{A}^{2} \mathrm{~T}_{\mathrm{s}}}{2 !}+\cdots+\frac{\mathrm{A}^{\mathrm{n}} \mathrm{T}_{\mathrm{s}}}{\mathrm{n} !}
\end{aligned}
$$

Eq. (6), Then they been divided by Tn, be re written in the following as:

$\dot{X}=\mathrm{AX}+\mathrm{Bu}$

where:

$$
\begin{aligned}
& \dot{X}=\left[\begin{array}{c}
\frac{d_{\mathrm{sD}}}{d t} \\
\frac{d_{\mathrm{s}_{\mathrm{SQ}}}}{\mathrm{dt}}
\end{array}\right] ; \quad \mathrm{X}=\left[\begin{array}{l}
\mathrm{i}_{\mathrm{sD}} \\
i_{\mathrm{sQ}}
\end{array}\right] ; \mathrm{u}=\left[\begin{array}{c}
\mathrm{v}_{\mathrm{sD}} \\
\mathrm{v}_{\mathrm{sQ}} \\
\widehat{\Psi}_{\mathrm{rD}} \\
\widehat{\Psi}_{\mathrm{rQ}}
\end{array}\right] \\
& A=\left[\begin{array}{cc}
-\left(1+\frac{x_{m}^{2}}{x_{r}^{2}}\right) \frac{r_{s}}{x_{s} \sigma} & 0 \\
0 & -\left(1+\frac{x_{m}^{2}}{x_{r}^{2}}\right) \frac{r_{s}}{x_{s} \sigma}
\end{array}\right] \text {; } \\
& \mathrm{B}=\left[\begin{array}{cccc}
\frac{1}{\mathrm{x}_{\mathrm{s}} \sigma} & 0 & \frac{1}{\mathrm{x}_{\mathrm{s}} \sigma} \frac{\mathrm{r}_{\mathrm{r}} \mathrm{x}_{\mathrm{m}}}{\mathrm{x}_{\mathrm{r}}^{2}} & \frac{1}{\mathrm{x}_{\mathrm{s}} \sigma} \frac{\mathrm{x}_{\mathrm{m}} \omega_{\mathrm{r}}}{\mathrm{x}_{\mathrm{r}}} \\
0 & \frac{1}{\mathrm{x}_{\mathrm{s}} \sigma} & -\frac{1}{\mathrm{x}_{\mathrm{s}} \sigma} \frac{\mathrm{x}_{\mathrm{m}} \omega_{\mathrm{r}}}{\mathrm{x}_{\mathrm{r}}} & \frac{1}{\mathrm{x}_{\mathrm{s}} \sigma} \frac{\mathrm{r}_{\mathrm{r}} \mathrm{x}_{\mathrm{m}}}{\mathrm{x}_{\mathrm{r}}^{2}}
\end{array}\right] ;
\end{aligned}
$$

Its corresponding discrete model is, therefore, given by:

$$
\widehat{X}(k)=e^{[A] T_{s}} X(k-1)+\left(e^{A T_{s}}-I\right) A^{-1} B u(k-1)
$$

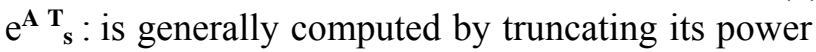
series ex pansion, i.e.,

If $n=1$, the simple forward Euler method is obtained, which gives the following finite where marks the variables estimated with the adaptive model and is the current time sample. A neural network can reproduce these equations, where are the weights of the neural networks defined as:

$$
\mathrm{w}_{1}=1-\frac{\mathrm{T}_{\mathrm{s}} \mathrm{r}_{\mathrm{s}}}{\sigma \mathrm{L}_{\mathrm{s}}}-\frac{\mathrm{T}_{\mathrm{s}} \mathrm{L}_{\mathrm{m}}}{\sigma \mathrm{L}_{\mathrm{s}} \mathrm{L}_{\mathrm{r}} \mathrm{T}_{\mathrm{r}}} ; \mathrm{w}_{2}=\frac{\mathrm{T}_{\mathrm{s}}}{\sigma \mathrm{L}_{\mathrm{s}}} ; \mathrm{w}_{3}=\frac{\mathrm{T}_{\mathrm{s}} \mathrm{L}_{\mathrm{m}}}{\sigma \mathrm{L}_{\mathrm{s}} \mathrm{T}_{\mathrm{r}}} ; \mathrm{w}_{4}=\frac{\mathrm{T}_{\mathrm{s}} \mathrm{L}_{\mathrm{m}} \hat{\omega}_{\mathrm{r}}}{\sigma \mathrm{L}_{\mathrm{s}} \mathrm{L}_{\mathrm{r}}}
$$

where: $\hat{\mathrm{i}}_{\mathrm{s}}(\mathrm{k})$ the current variables estimated with the adaptive model and $\mathrm{k}$ is the current time sample. An artificial neural network (ANN) can reproduce these equations, where $\mathrm{w} 1, \mathrm{w} 2, \mathrm{w} 3, \mathrm{w} 4$ are the weights of the neural networks defined as (11); Ts is the sampling time for the stator current observer. The ANN has, thus, four inputs and two outputs [25]-[26]. In the ANN, the weights $\mathrm{w} 1, \mathrm{w} 2$ and $\mathrm{w} 3$ are kept constant to their values computed offline while only w4 is adopted online.
These equations are the same as those obtained in [26]. In the scheme is presented in [26], the adaptive model is characterized by the feedback of delayed estimated stator current components to the input of the neural network, which means that the adaptive model employed is in simulation mode. Moreover, thela)daptive model is tuned online (training) by means of a BPN algorithm, however, nonlinear in its nature with the consequent drawbacks (local minima, heuristics in the choice of the network parameters, paralysis, convergence problems).

In this TLS SC MRAS observer proposed, the adaptive model based on the ADALINE has been improved, A linear TLS algorithm, which is more suitable than a nonlinear one, like the BPN, is used to reduce the computation effort and overcome some drawbacks, which cause by its inherent nonlinearity. 
Furthermore, the employment of the adaptive model in prediction mode leads to a quicker convergence of the algorithm, a higher bandwidth of the speed control loop, a better behavior at zero-speed, lower speed estimation errors both in transient and steady-state conditions.

An integration method more efficient than that used in (12) is the so-called modified Euler integration, which also takes into consideration the values of the variables in two previous time steps [29]. From (6), the following discrete time equations can be obtained, as shown in (12). Also, in this case, a neural network can reproduce these equations, where and are the weights of the neural networks defined as (13).

Rearranging (12), the matrix equation is obtained in prediction mode; see (14). This matrix equation can be solved by any least-square technique. (14)

Matrix equation (14) can be written: $A x \approx b$, This is a classical matrix equation of the type, where $\mathrm{A}$ is called a "data matrix", b is called an"observation vector," and A is the scalar unknown. In this application a classical LS algorithm in a recursive form has been employed; This algorithm is described in detail in [30]. Fig. 2 shows the block diagram of the LS_SC_MRAS speed observer. In literature there exist three Least-Squares techniques, i.e. the Ordinary Least-Squares (OLS), the Total LeastSquares (TLS) and the Data Least-Squares(DLS) which arise when errors are respectively present only in $b$ or both in A and in b or only in A. The LS technique solves for this problem by calculating the value of $\omega r$ which minimises the sum of squares of the distances among the elements (ai, bi), with $\mathrm{i}=1, \ldots, \mathrm{m}$, and the line itself. OLS minimises the sum of squares of the distances in the $\mathrm{b}$ direction (error only in the observation vector). TLS minimises the sum of squares in the direction orthogonal to the line (for this reason TLS is also called orthogonal regression) while DLS minimises the sum of squares in the A direction (errors only in the data matrix).

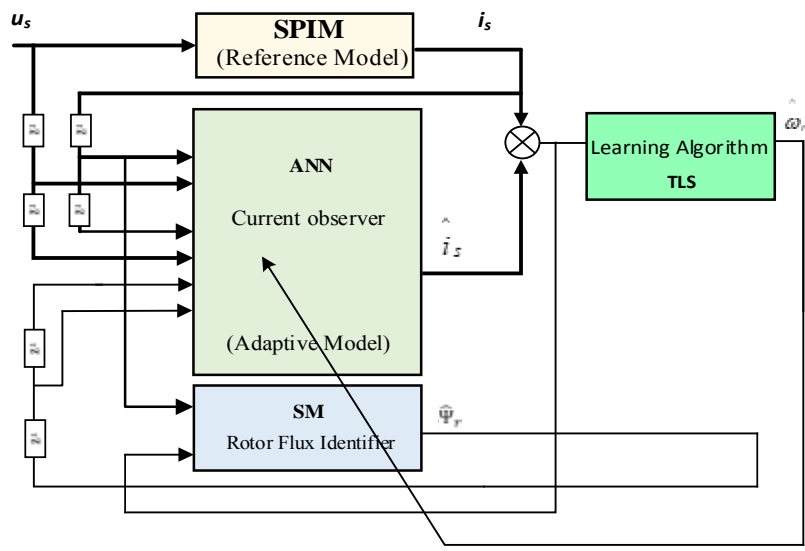

Fig. 2 LS_SC_MRAS speed observer

$$
\begin{aligned}
& \hat{\mathrm{i}}_{\mathrm{sD}(\mathrm{k})}=\mathrm{w}_{1} \mathrm{i}_{\mathrm{sD}(\mathrm{k}-1)}+\mathrm{w}_{2} \mathrm{u}_{\mathrm{sD}(\mathrm{k}-1)}+\mathrm{w}_{3} \hat{\psi}_{\mathrm{rD}(\mathrm{k}-1)}+\mathrm{w}_{4} \hat{\psi}_{\mathrm{rQ}(\mathrm{k}-1)}+\mathrm{w}_{5} \mathrm{i}_{\mathrm{sD}(\mathrm{k}-2)}-\mathrm{w}_{6} \mathrm{u}_{\mathrm{sD}(\mathrm{k}-2)}-\mathrm{w}_{7} \hat{\psi}_{\mathrm{rD}(\mathrm{k}-2)}-\mathrm{w}_{8} \hat{\psi}_{\mathrm{rQ}(\mathrm{k}-2)} \\
& \hat{\mathrm{i}}_{\mathrm{sQ}(\mathrm{k})}=\mathrm{w}_{1} \mathrm{i}_{\mathrm{sQ}(\mathrm{k}-1)}+\mathrm{w}_{2} \mathrm{u}_{\mathrm{sQ}(\mathrm{k}-1)}+\mathrm{w}_{3} \hat{\psi}_{\mathrm{rQ}(\mathrm{k}-1)}-\mathrm{w}_{4} \hat{\psi}_{\mathrm{rD}(\mathrm{k}-1)}+\mathrm{w}_{5} \mathrm{i}_{\mathrm{sQ}(\mathrm{k}-2)}-\mathrm{w}_{6} \mathrm{u}_{\mathrm{sQ}(\mathrm{k}-2)}-\mathrm{w}_{7} \hat{\psi}_{\mathrm{rQ}(\mathrm{k}-2)}+\mathrm{w}_{8} \hat{\psi}_{\mathrm{rD}(\mathrm{k}-2)} \\
& \mathrm{w}_{1}=1-\frac{3 \mathrm{TR}_{\mathrm{s}}}{2 \sigma \mathrm{L}_{\mathrm{s}}}-\frac{3 \mathrm{TL}_{\mathrm{m}}^{2}}{2 \sigma \mathrm{L}_{\mathrm{r}} \mathrm{L}_{\mathrm{s}} \mathrm{T}_{\mathrm{r}}} ; \mathrm{w}_{2}=\frac{3 \mathrm{~T}}{2 \sigma \mathrm{L}_{\mathrm{s}}} ; \mathrm{w}_{3}=\frac{3 \mathrm{TL}_{\mathrm{m}}}{2 \sigma \mathrm{L}_{\mathrm{r}} \mathrm{L}_{\mathrm{s}} \mathrm{T}_{\mathrm{r}}} ; \mathrm{w}_{4}=\frac{3 \mathrm{TL}_{\mathrm{m}}}{2 \sigma \mathrm{L}_{\mathrm{r}} \mathrm{L}_{\mathrm{s}}} \omega_{\mathrm{r}} ; \mathrm{w}_{5}=\frac{3 \mathrm{TR}_{\mathrm{s}}}{2 \sigma \mathrm{L}_{\mathrm{s}}}+\frac{\mathrm{TL}_{\mathrm{m}}^{2}}{2 \sigma \mathrm{L}_{\mathrm{r}} \mathrm{L}_{\mathrm{s}} \mathrm{T}_{\mathrm{r}}} ; \\
& \mathrm{w}_{6}=\frac{\mathrm{T}}{2 \sigma \mathrm{L}_{\mathrm{s}}} ; \mathrm{w}_{7}=\frac{\mathrm{TL}_{\mathrm{m}}}{2 \sigma \mathrm{L}_{\mathrm{r}} \mathrm{L}_{\mathrm{s}} \mathrm{T}_{\mathrm{r}}} ; \mathrm{w}_{8}=\frac{\mathrm{TL}_{\mathrm{m}}}{2 \sigma \mathrm{L}_{\mathrm{r}} \mathrm{L}_{\mathrm{s}}} \omega_{\mathrm{r}} \\
& \mathrm{A}=\left[\begin{array}{c}
\mathrm{A}_{1} \\
\mathrm{~A}_{2}
\end{array}\right]=\left[\begin{array}{c}
\frac{3 \mathrm{~T} \mathrm{~L}_{\mathrm{m}}}{2 \sigma \mathrm{L}_{\mathrm{r}} \mathrm{L}_{\mathrm{s}}} \hat{\psi}_{\mathrm{rQ}(\mathrm{k}-1)}-\frac{\mathrm{T} \mathrm{L}_{\mathrm{m}}}{2 \sigma \mathrm{L}_{\mathrm{r}} \mathrm{L}_{\mathrm{s}}} \hat{\psi}_{\mathrm{rQ}(\mathrm{k}-2)} \\
-\frac{3 \mathrm{~T} \mathrm{~L}_{\mathrm{m}}}{2 \sigma \mathrm{L}_{\mathrm{r}} \mathrm{L}_{\mathrm{s}}} \hat{\psi}_{\mathrm{rD}(\mathrm{k}-1)}+\frac{\mathrm{TL_{ \textrm {m } }}}{2 \sigma \mathrm{L}_{\mathrm{r}} \mathrm{L}_{\mathrm{s}}} \hat{\psi}_{\mathrm{rD}(\mathrm{k}-2)}
\end{array}\right]
\end{aligned}
$$$$
\text { minimization yields the corresponding solution. This }
$$
error is given by:$$
\mathbf{E}_{(\mathrm{X})}=\frac{(\mathrm{Ax}-\mathrm{b})^{\mathrm{T}}(\mathrm{Ax}-\mathrm{b})}{1-\xi+\xi x^{T} x}
$$

where $\mathrm{T}$ represents the transpose and $\xi$ is equal to 0.5 for $\mathrm{b}=\left[\begin{array}{c}\mathrm{b}_{1} \\ \mathrm{~b}_{2}\end{array}\right]=\left[\begin{array}{l}\hat{\mathrm{i}}_{\mathrm{sQ}(\mathrm{k})}-\mathrm{w}_{1} \mathrm{i}_{\mathrm{sQ}(\mathrm{k}-1)}-\mathrm{w}_{2} \mathrm{u}_{\mathrm{sQ}(\mathrm{k}-1)}-\mathrm{w}_{3} \hat{\psi}_{\mathrm{rQ}(\mathrm{k}-1)}-\mathrm{w} \\ \hat{\mathrm{i}}_{\mathrm{sQ}(\mathrm{k})}-\mathrm{w}_{1} \mathrm{i}_{\mathrm{sQ}(\mathrm{k}-1)}-\mathrm{w}_{2} \mathrm{u}_{\mathrm{sQ}(\mathrm{k}-1)}-\mathrm{w}_{3} \psi_{\mathrm{rQ}(\mathrm{k}-1)}-\mathrm{w}_{5}\end{array}\right.$ TLS, 1 for DLS and 0 for QLS. Depending on where the

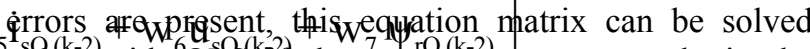
either with $\mathrm{OLS}^{\mathrm{S}}$ if the errors are present only in the observation vector, or with data OLS (DLS) if the errors

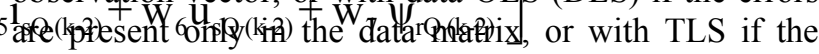
errors are present both in the data matrix and in the observation vector [30].

\section{B. Rotor Speed Estimation Algorithm}

Formula (14), which is a classical matrix equation of the type $A x \approx b$, where $A$ is called "data matrix", $b$ is called "observation vector," and $\mathrm{x}$ is the vector consisting only of the unknown scalar $\omega r$.

$A x \approx b$ is the linear regression problem under hand. All LS problems have been generalized by using a parameterized formulation (generalized LS) of an error function whose the dq-axis components of the rotor flux linkage which can be affected by errors and noise resulting from input stator current measurements, and the same can be said for the observation vector which is also composed of dq components of the rotor flux, the stator current, voltage: Therefore TLS will be a algorithm more appropriate than an OLS or a DLS algorithm. 
Using TLS algorithm, this error is given by:

$$
E_{\left(\omega_{r}\right)}=\frac{(A x-b)^{T}(A x-b)}{1+x^{T} x}=\frac{\left(a_{i}^{T} \omega-b_{i}\right)^{2}}{1+\omega_{r}^{2}}=\frac{\rho^{2}}{1+\omega_{r}^{2}}
$$

Remark that $(\mathrm{Ax}-\mathrm{b})$ is the dq axis vector error between the stator current from the reference model (SPIM) and the estimated current by the neural network, i.e,

$$
\rho=\left[\begin{array}{c}
\varepsilon_{i s D} \\
\varepsilon_{i s Q}
\end{array}\right]=\left[\begin{array}{c}
i_{s D}-\hat{i}_{s D} \\
\hat{i}_{s Q}-\hat{i}_{s Q}
\end{array}\right]
$$

This error can be minimized with a gradient descent method. In [],[], this gives rise to the following speed adaptation law:

The corresponding steepest descent discrete time formula is given by:

$$
\hat{\omega}_{r}(k)=\hat{\omega}_{r}(k-1)+\Delta \omega_{r}
$$

$$
\begin{aligned}
\Delta \omega_{r} & =-\eta \frac{d E}{d \omega_{r}} \\
\frac{d E}{d \omega_{r}} & =\frac{\rho a_{i}}{\left(1+\omega_{r}^{2}\right)}-\frac{\rho^{2} \omega}{\left(1+\omega_{r}^{2}\right)^{2}}
\end{aligned}
$$

Substituting (19), (20) to Equation (18), we get the following modifed equation:

$$
\begin{aligned}
\hat{\omega_{r}}(k) & =\hat{\omega}_{r}(k-1)-\eta\left(\frac{a_{i} \rho}{\left(1+\omega^{2}\right)}-\frac{\rho^{2} \omega}{\left(1+\omega^{2}\right)^{2}}\right) \\
& =\hat{\omega}_{r}(k-1)-\eta \delta+\eta \delta^{2} \omega
\end{aligned}
$$

where:

$$
\delta=\frac{\rho}{\left(1+\omega^{2}\right)}
$$

$\eta$ is the learning rate, ai $(\mathrm{k})$ is the row of A fed at instant $\mathrm{k}$, and $\mathrm{bi}(\mathrm{k})$ is the corresponding observation at instant $\mathrm{k}$.

This is the TLS learning law [30] and is its cost function. The TLS is a linear unit with inputs (ai vector), weights (vector $\omega$ ), one output (scalar), and one training error (scalar $\rho(\mathrm{k})$ ).

where:

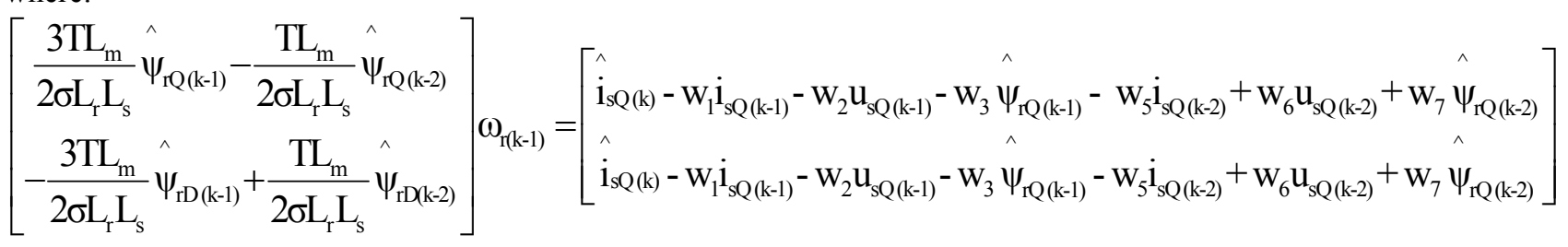

\section{Rotor Flux Estimation and Stability Analysis of}

\section{Observer}

Consider a non-linear system described by:

$$
\left\{\begin{array}{l}
\dot{\mathrm{z}}=\mathrm{F}\left(\omega_{r}\right) \mathrm{z}+\mathrm{G}\left(\mathrm{u}, \omega_{r}, \mathrm{z}\right) \\
\mathrm{y}=\mathrm{Cz}
\end{array}\right.
$$

where:

$$
\begin{aligned}
& \begin{array}{l}
y=z_{1}=\left[\begin{array}{l}
i_{s D} \\
i_{s Q}
\end{array}\right] ; z_{2}=\left[\begin{array}{l}
\varphi_{r D} \\
\varphi_{r Q}
\end{array}\right] ; u=\left[\begin{array}{l}
u_{s D} \\
u_{s Q}
\end{array}\right] ; \\
F_{1}\left(\omega_{r}\right)=\left[\begin{array}{cc}
\frac{K}{T_{r}} & K \omega_{r} \\
-K \omega_{r} & \frac{K}{T_{r}}
\end{array}\right] ; K=\frac{L_{m}}{\sigma L_{r} L_{s}} ; \sigma=1-\left(\frac{L_{m}^{2}}{\sigma L_{r} L_{s}}\right) \\
g_{1}\left(u, \omega, z_{1}\right)=\left[\begin{array}{l}
-\gamma i_{s D}+\left(\frac{1}{\sigma L_{s}}\right) u_{s D} \\
-\gamma i_{s Q}+\left(\frac{1}{\sigma L_{s}}\right) u_{s Q}
\end{array}\right] ; \gamma=\left(\frac{R_{s}}{\sigma L_{s}}\right)+\left(R_{r} \frac{L_{m}^{2}}{\sigma L_{r} L_{s}}\right) \\
; g_{2}\left(u, \omega, z_{2}\right)=\left[\begin{array}{l}
\left(\frac{L_{m}}{T_{r}}\right) i_{s D}-\left(\frac{1}{T_{r}}\right) \varphi_{r D}-\omega_{r} \varphi_{r Q} \\
\left(\frac{L_{m}}{T_{r}}\right) i_{s Q}-\left(\frac{1}{T_{r}}\right) \varphi_{r Q}+\omega_{r} \varphi_{r D}
\end{array}\right] ;
\end{array}
\end{aligned}
$$

If the system is observable, the objective of the observer is to give the best state variables. From the measurement of output $\mathrm{y}$ and input $\mathrm{u}$, the observer is defined by the follow structure:

$$
\dot{\hat{z}}=F\left(\omega_{r}\right) \hat{z}+G\left(u, \omega_{r}, \hat{z}\right)+\Lambda I_{s}
$$

where $\Lambda$ is the gain matrix and $I s$ is a vector defined by:

$$
I_{s}=\left[\operatorname{sign}\left(s_{1}\right) \quad \operatorname{sign}\left(s_{2}\right)\right]^{T}
$$

With $\mathrm{S}$ is the slide surface of the observer is defined as following:

$$
S=\left[\begin{array}{ll}
s_{1} & s_{2}
\end{array}\right]^{T}=\left[\begin{array}{ll}
i_{s D}-\hat{i}_{s D} & i_{s Q}-\hat{i}_{s Q}
\end{array}\right]^{T}
$$

Subtracting Eq.16 and Eq.17 gives:

$$
\dot{\varepsilon}=\left[F\left(\omega_{r}\right) z-F\left(\omega_{r}\right) \hat{z}+G\left(u, \omega_{r}, z\right)-G\left(u, \omega_{r}, \hat{z}\right)\right]-\Lambda I_{s}
$$

With $\varepsilon$ is the error vector defined by:

$$
\begin{aligned}
\varepsilon & =\left[\begin{array}{llll}
\varepsilon_{1} & \varepsilon_{2} & \varepsilon_{3} & \varepsilon_{4}
\end{array}\right]^{T} \\
& =\left[\begin{array}{lllll}
i_{s D}-\hat{i}_{s D} & i_{s Q}-\hat{i}_{s Q} & \varphi_{r D}-\hat{\varphi}_{r D} & \varphi_{r Q}-\hat{\varphi}_{r Q}
\end{array}\right]^{T}
\end{aligned}
$$

The aim of this section is to estimate the rotor flux components based on the stator currents and voltages that 
are easily measurable. From (17), the flux estimation algorithm based on sliding-mode theory is defined:

$$
\left\{\begin{array}{l}
\dot{\hat{\varphi}}_{r D}=\left(\frac{L_{m}}{T_{r}}\right) i_{s D}-\left(\frac{1}{T_{r}}\right) \hat{\varphi}_{r D}-\hat{\omega}_{r} \hat{\varphi}_{r Q}+\Lambda_{\varphi r D} I_{s} \\
\dot{\hat{\varphi}}_{r Q}=\left(\frac{L_{m}}{T_{r}}\right) i_{s Q}-\left(\frac{1}{T_{r}}\right) \hat{\varphi}_{r Q}+\hat{\omega}_{r} \hat{\varphi}_{r D}+\Lambda_{\varphi r Q} I_{s}
\end{array}\right.
$$

From (20), the dynamic of the estimation error is given by:

$$
\left\{\begin{array}{l}
\dot{\varepsilon}_{1}=\left(\frac{K}{T_{r}}\right) \varepsilon_{3}+K \omega_{r} \varepsilon_{4}-\Lambda_{i s D} I_{s} \\
\dot{\varepsilon}_{2}=\left(\frac{K}{T_{r}}\right) \varepsilon_{4}-K \omega_{r} \varepsilon_{3}-\Lambda_{i s Q} I_{s} \\
\dot{\varepsilon}_{3}=\left(-\frac{1}{T_{r}}\right) \varepsilon_{3}-\omega_{r} \varepsilon_{4}-\Lambda_{\varphi r D} I_{s} \\
\dot{\varepsilon}_{4}=\left(-\frac{1}{T_{r}}\right) \varepsilon_{4}+\omega_{r} \varepsilon_{3}-\Lambda_{\varphi r Q} I_{s}
\end{array}\right.
$$

By defining Lyapunov function as:

$$
V=\frac{1}{2} S^{T} S
$$

Whose time derivative is,

$$
\frac{d V}{d t}=S^{T} \frac{d S}{d t}=\left[\begin{array}{ll}
\varepsilon_{1} & \varepsilon_{2}
\end{array}\right]\left[\begin{array}{l}
\left(\frac{K}{T_{r}}\right) \varepsilon_{3}+K \omega_{r} \varepsilon_{4}-\Lambda_{i s D} I_{s} \\
\left(\frac{K}{T_{r}}\right) \varepsilon_{4}-K \omega_{r} \varepsilon_{3}-\Lambda_{i s Q} I_{s}
\end{array}\right]
$$

When the currents trajectory reaches the sliding surface $\varepsilon_{1}=\varepsilon_{2}=0$, the observer error dynamics given by $(25)$ behaves, in the sliding-mode as a reduced order system governed only by the roto flux error, because $\varepsilon_{i s}=\dot{\varepsilon}_{i s}=0$

In order to demonstrate the stability of the previous system, the following Lyapunov function candidate is proposed:

$$
V=\frac{1}{2}\left[\begin{array}{ll}
\varepsilon_{3} & \varepsilon_{4}
\end{array}\right]\left[\begin{array}{ll}
\varepsilon_{3} & \varepsilon_{4}
\end{array}\right]^{T}
$$

The time derivative of the Lyapunov function candidate is:

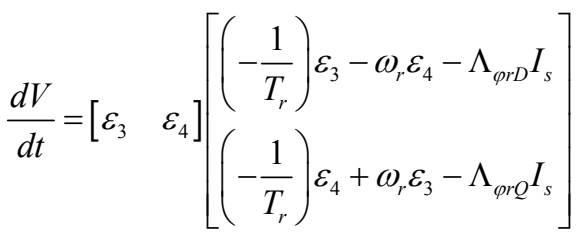

When sliding takes place:

$$
\left[\begin{array}{cc}
\Lambda_{\varphi r D} & 0 \\
0 & \Lambda_{\varphi r Q}
\end{array}\right]=-\Lambda\left[\begin{array}{cc}
\frac{1}{T_{r}} & \omega_{r} \\
-\omega_{r} & \frac{1}{T_{r}}
\end{array}\right]\left[\begin{array}{l}
\varepsilon_{3} \\
\varepsilon_{4}
\end{array}\right]=-\Lambda \Gamma\left[\begin{array}{l}
\varepsilon_{3} \\
\varepsilon_{4}
\end{array}\right]
$$

Choose $\Lambda=\Delta \Gamma^{-1}$ where $\Delta=\left[\begin{array}{cc}\delta_{1} & -\omega_{r} \\ \omega_{r} & \delta_{2}\end{array}\right]$ and $\delta_{1}, \delta_{2}$ are positive design constants.

Note that $\operatorname{det}\left(\Gamma\left(\omega_{r}\right)\right) \neq 0$ for all $\omega_{r}$ and so the inverse always exist. From (23), when sliding takes place, substituting from (28) yields:

$$
\left[\begin{array}{c}
\dot{\varepsilon}_{3} \\
\dot{\varepsilon}_{4}
\end{array}\right]=\left\{\left[\begin{array}{cc}
-\frac{1}{T_{r}} & -\omega_{r} \\
\omega_{r} & -\frac{1}{T_{r}}
\end{array}\right]-\Delta \Gamma^{-1} \Gamma\right\}\left[\begin{array}{l}
\varepsilon_{3} \\
\varepsilon_{4}
\end{array}\right]=\left[\begin{array}{cc}
\left(-\frac{1}{T_{r}}\right)-\delta_{1} & 0 \\
0 & \left(-\frac{1}{T_{r}}\right)-\delta_{2}
\end{array}\right]
$$

This is, the flux observer error converges to zero with exponential rate of convergence.

\section{SIMULINK AND DISCUSSION}

In order to verify and evaluate the performance of the SC MRAS observer using NN and SM a sensorless vector control of SPIM drive system, as shown in Fig. 6 has been simulated at different speed ranges through Matlab simulation software, specially surveyed at low speed range. Tests in this section are conducted based on recommended benchmark tests [23, 24, 32, 33, 34]. SPIM parameters: $1 \mathrm{HP}, 220 \mathrm{~V}, 50 \mathrm{~Hz}, 4$ pole, $1450 \mathrm{rpm}$. Rs = $10.1 \Omega, \mathrm{Rr}=9.8546 \Omega, \mathrm{Ls}=0.833457 \mathrm{H}, \mathrm{Lr}=0.830811$ $\mathrm{H}, \mathrm{m}=0.783106 \mathrm{H}, \mathrm{Ji}=0.0088 \mathrm{~kg} \cdot \mathrm{m} 2$. The simulation results show the performance of the proposed estimator in different conditions: during speed reversal, low speed operation, ramp response, effect of parameter variation and during the regenerating mode operation.

\section{A. Dynamic Performance:}

In this first part, the dynamic performance of the drive and observer have been verified by the tests are conducted based on recommended Benchmark tests in [23], [33]. Test 1 presents rapid transitions and operating areas at large and zero speeds, Test 2 consists of low and very low speed operation and reversal. In Test 1, the reference speed are imposed from zero increased to $125 \mathrm{rad} / \mathrm{s}$ and constant up to $4 \mathrm{~s}$. Then, it is reduced to zero. Between $2,5 \mathrm{~s}$ and $4,8 \mathrm{~s}$, a quasisymmetric velocity profile is imposed in the opposite rotational direction, defining a second area of critical operating at $-125 \mathrm{rad} / \mathrm{s}$ between $5 \mathrm{~s}$ and $6 \mathrm{~s}$ and constant up to $10 \mathrm{~s}$. Then, the motor speed is again reduced to zero. Rated load is applied at $2 \mathrm{~s}$ and rejected at $4 \mathrm{~s}$, at $7 \mathrm{~s}$ and rejected at $9 \mathrm{~s}$, respectively with -rated load is applied. The application and removal of a torque load at the moments will also assess the impact of this type of disturbance at the high speed operations. 


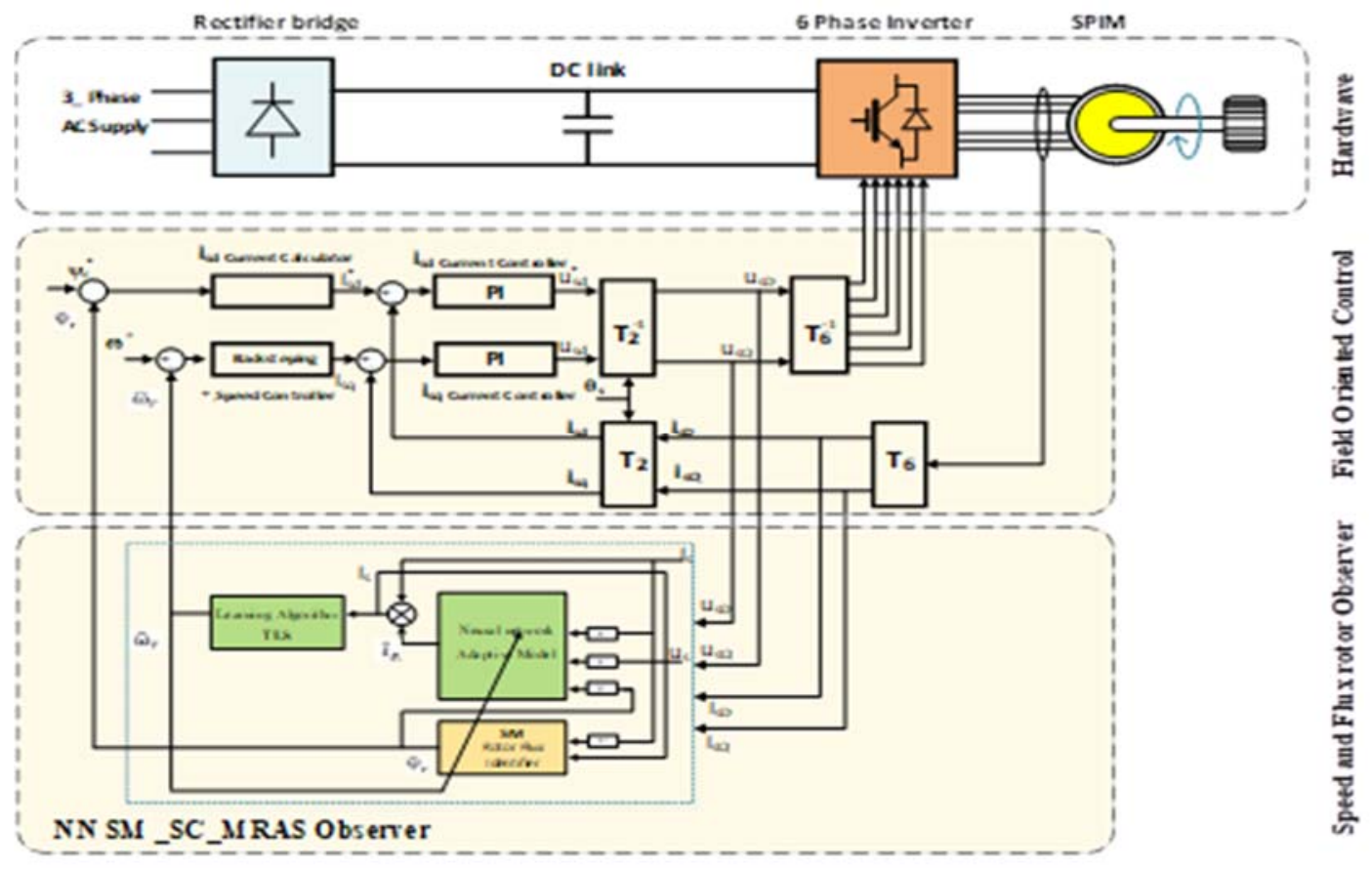

Fig. 3 Sensorless vector control of SPIM drive using LS_SC_MRAS observer 

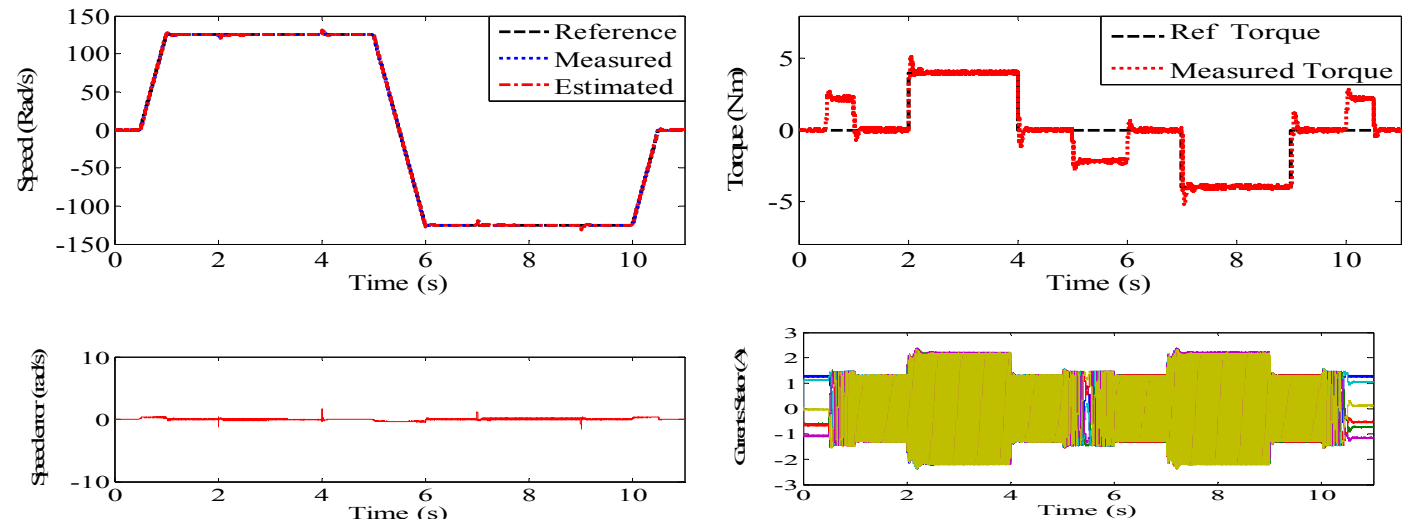

Fig. 4 The performance of NNSM_SC_MRAS obsever during high speed reveral

(a) Speed responses and error, respectively; (b) Stator current phase A and torque respone

The results in Fig.4 show the speed responses, thre speed estimation error, the stator current and torque during test 1 . From these simulation results show that although surveyed with larger speed range compare to in [33] (Fig. 2a)), the estimation performance of NNSM_SC_MRAS observer is very good at high, low and zero speed and reversal. The speed estimation error is the estimated speed perfectly follows the rotor speed with good
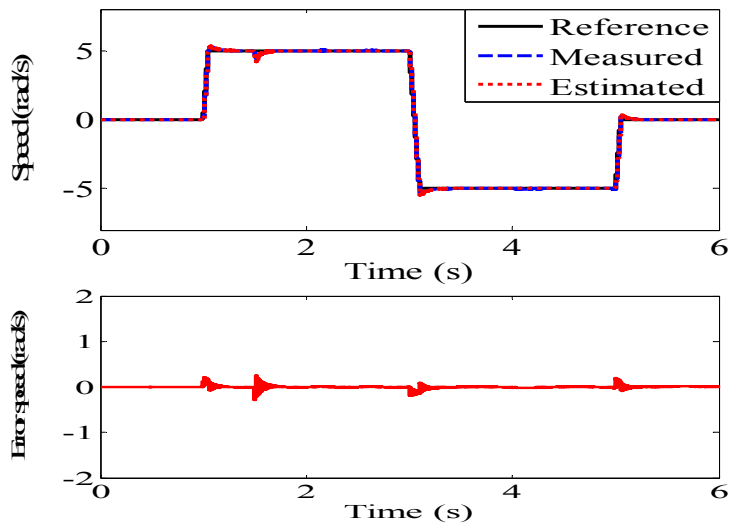

a)

c)

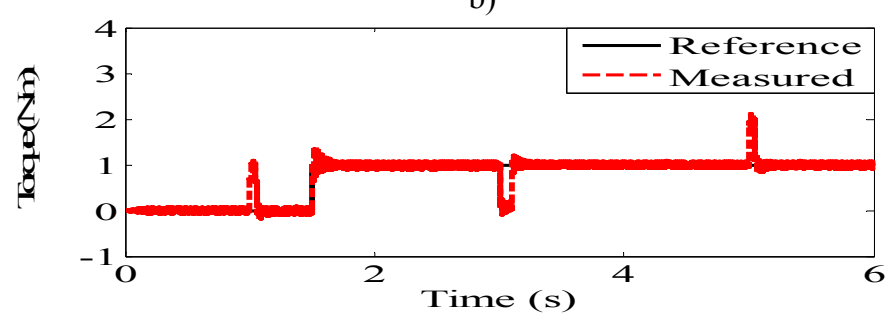

Fig. 5 The performance of NNSM_SC_MRAS obsever during low speed reveral

(a) Speed responses and error, respectively ; (b) Rotor flux responses and error, respectivel; (c) Torque responses behavior in terms of tracking and disturbance rejection. The proposed schemes in [23]; [33]; and NNSM_SC_MRAS scheme, the speed reversal is accomplished in less than $1 \mathrm{~s}$ and that the torque response is instantaneous. The speed error is maximum at zero crossing and during the speed transient and it is about as much as $0.105 \mathrm{rad} / \mathrm{s}$ in NNSM_SC_MRAS observer, $0.5 \mathrm{rad} / \mathrm{s}$ in the proposed observer [23] (Fig. 4, 5, 6).
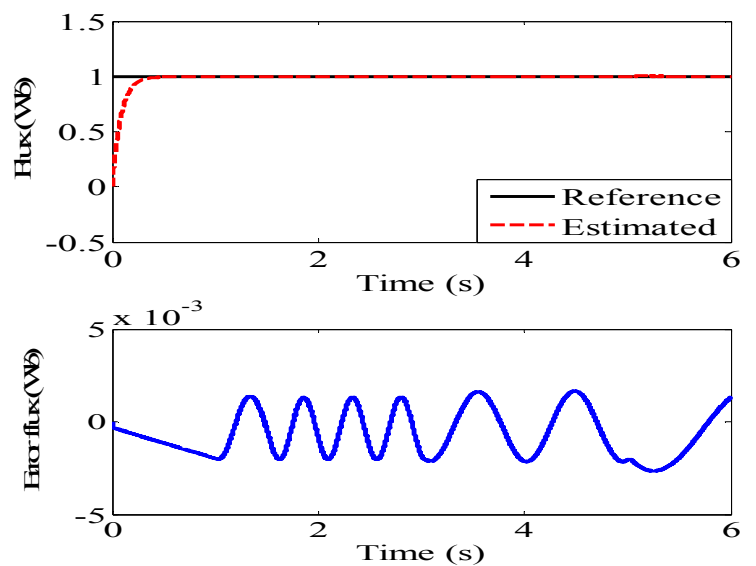

b) 
Furthermore, a speed reversal from $5 \mathrm{rad} / \mathrm{s}$ to $-5 \mathrm{rad} / \mathrm{s}$ and $8 \mathrm{rad} / \mathrm{s}$, at $25 \%$ load has been performed for testing the dynamic performances of the drive using NNSM-SC MRAS at low speed. Fig. 5 shows the speed and torque response of NNSM_SC_MRAS drive is very quick and that after few oscillations it converges to the reference value. We observe very small oscillations during transients and very low orientation errors in the two critical areas of the proposed observer. The application $25 \%$ load at 1.75 $\mathrm{s}$ and keep constant in the whole time of the remaining survey will also assess the impact of this type of regenerating mode operation. Using SM to identify rotor flux will avoid the instability in the regenerating mode, the survey time from $3 \mathrm{~s}$ to $6 \mathrm{~s}$, demonstrates this.

From two above tests, the speed estimation performance of the proposed observer, which are surveyed in the case of very high dynamics in Fig. 4 and Fig. 5 are very well, the maximum overshoot and the speed estimation error obtained with the NNSM SC MRAS observer are lower than the corresponding one with the observer [23], [33] and [34]. The torque response obtained with this
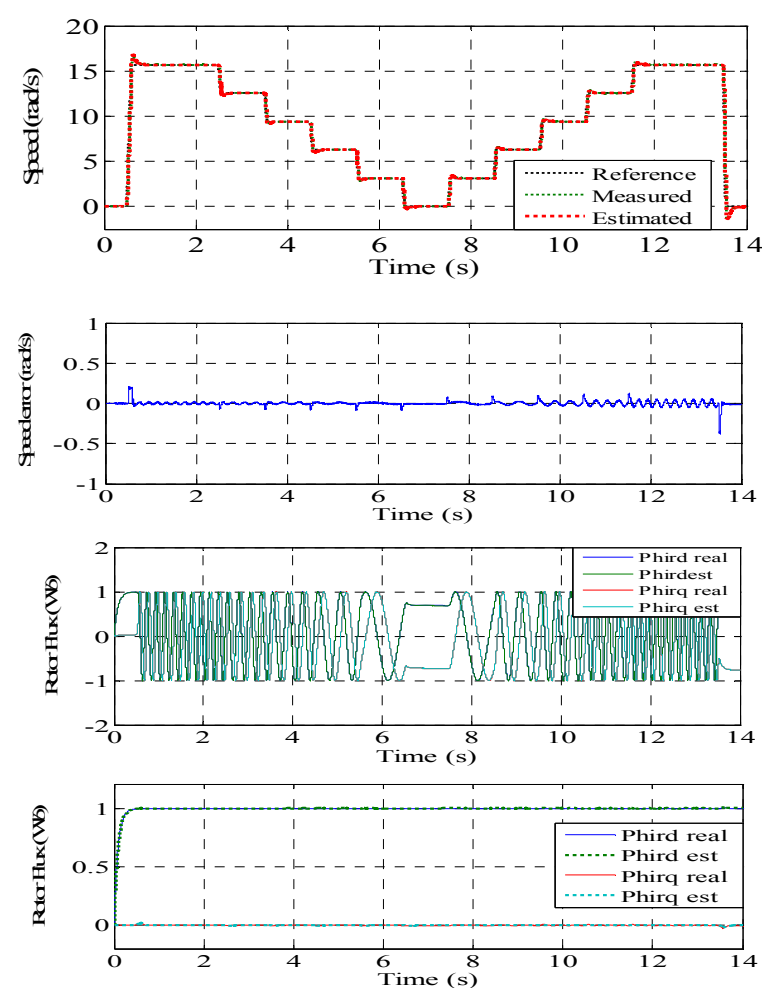

proposed observer is very smooth, while the corresponding one obtained with the the proposed observer in [34] is much affected by ripple ([34] Fig. $3 \mathrm{~b}, 4 \mathrm{~b})$, [33] the performance of the observer in case of low speed reversal is not surveyed]. The performance of the proposed scheme is very stable and very good in wide speed range.

\section{$B$. The performance of proposed observer in very} low speed ranges:

In this three test, the performance of the speed estimation has been verified in the very low and zero speed ranges based on proposed benchmark tests [24]. The drive has been given a speed reference step from $15 \mathrm{rad} / \mathrm{s}$ to zero then increase to $15 \mathrm{rad} / \mathrm{s}, 3$ $\mathrm{rad} / \mathrm{s}$ steps, $25 \%$ load applied at $2.5 \mathrm{~s}$ and rejected at $15 \mathrm{~s}$. Fig 6 a,b show the speed responses of proposed SC_MRAS at no load and $25 \%$ load, respectively. The simulink results show that no instability phenomena occur at low and zero speed range, the speed estimated error is not significantly. In contrast, with a proposed observer in [24] (Fig.7, Fig. 8) shows instability phenomena, the estimated error increase at low and zero speed range.
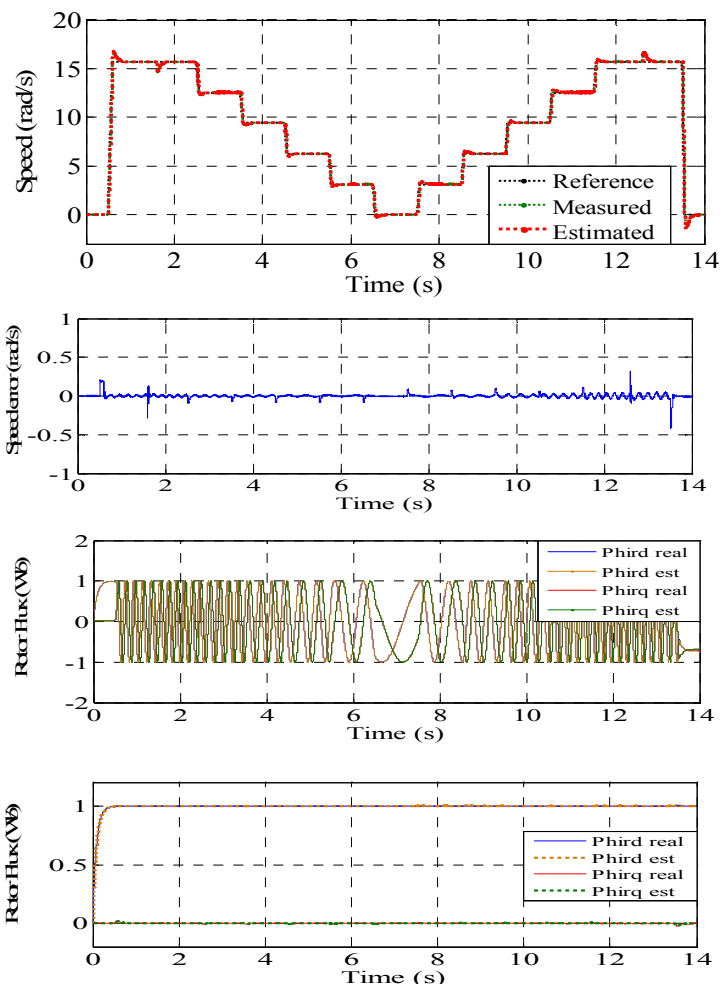

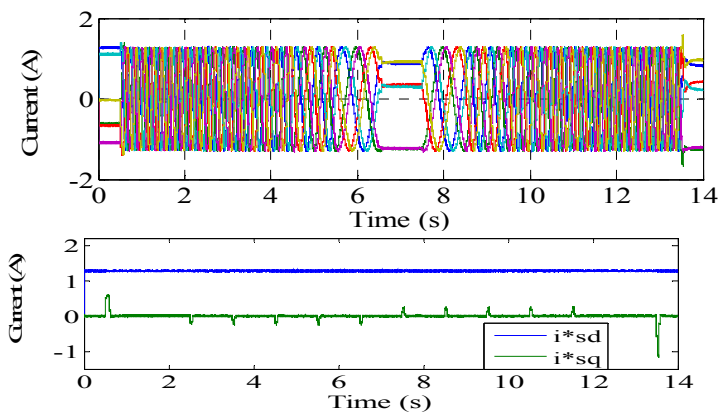

(a)
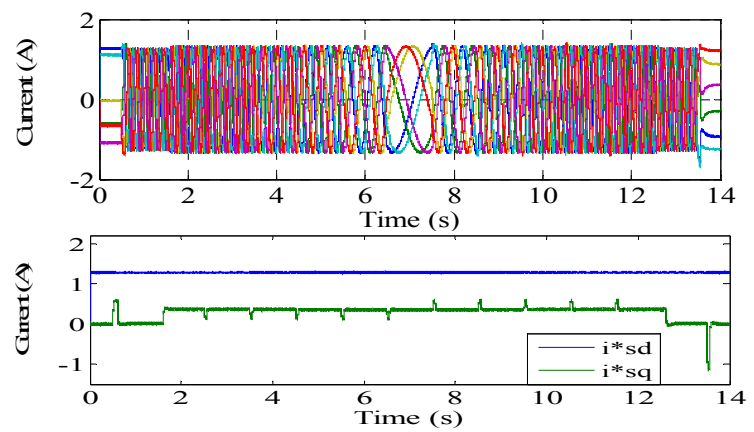

(b)
Another survey also is carried out to justify the effectiveness of the proposed method in the low speed region by providing the sets of ramp speed reference operation from 0 to $\pm 15 \mathrm{rad} / \mathrm{s}$ working with rated load, This tests is conducted based on recommended benchmark tests [32]. In any case, better results in the estimation accuracy at low speeds are to be expected with both NNSM_SC_MRAS and MRAS observers in [32]. The simulink results in Fig.7 and in [32] (Fig.4) show the performances of both the estimators for triangular speed command in both the forward and reverse motoring modes at rated load torque are very well. However, the zoom of speed figure show the speed deviation of NNSM_SC_MRAS estimator is less than the proposed MRAS estimator in [32]. For the MRAS observer, which is proposed in [32], the speed error the error between estimated, measured speed and reference higher, the convergence time of the estimated and measured speed to reference speed value are longer (Fig 4b) than NNSM SC MRAS obeserver. Using SM to estimate the rotor flux gives stability in the speed reveral, is not disturbed.
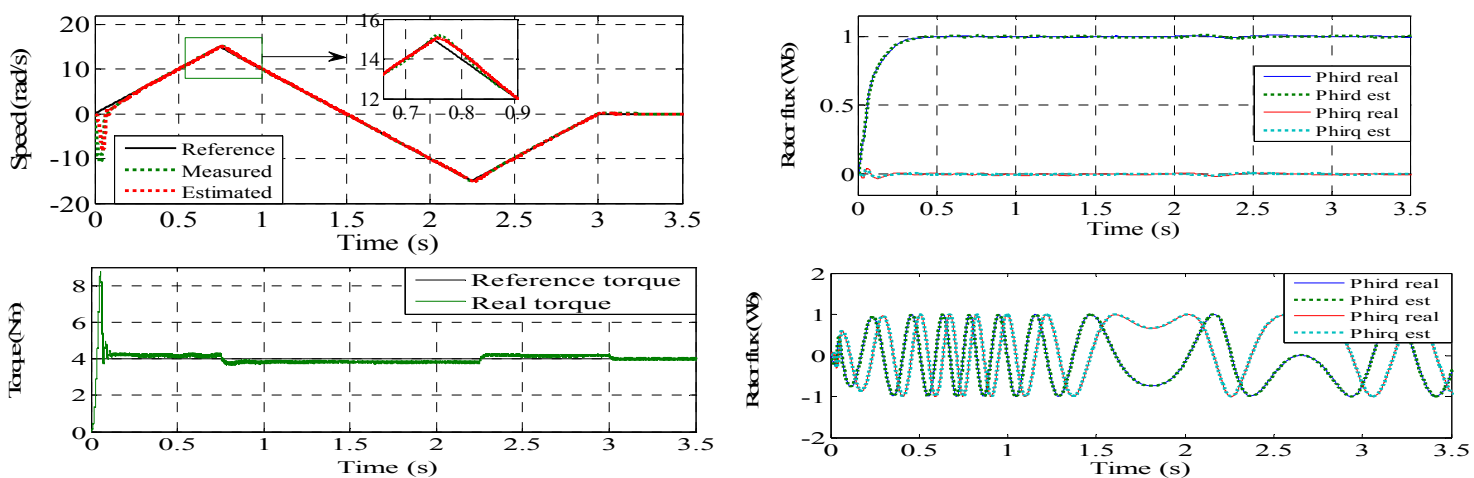

Fig. 7 The speed of the SPIM in very low speed ramp response

\section{Sensitivity to Stator Resistance Variation:}

The purpose of this test is to verify the speed estimation performance of the proposed MRAS observers for motor parameter variation. The drive and observer have been verified based on recommended benchmark tests in [23] but extending survey additionally case the resistance values increase $50 \%$. Fig. 8 shows the performance of the observer when Rs variations. Rs is increased $30 \%$ and $50 \%$, load is applied at $2 \mathrm{~s}$. The reference speed is increased from zero to $20 \mathrm{rad} / \mathrm{s}$, then is reduced to
$12 \mathrm{rad} / \mathrm{s}$ to $7 \mathrm{rad} / \mathrm{s}$ to zero. The stable operation and oscillating speed performance of the NNSM SC_MRAS observer (Fig. 8) and proposed observer in [23] (Fig.10) obtained are very well with Rs increases 30\%. For the proposed SC_MRAS, when increasing Rs up to $50 \%$, its performance is still well, the speed and rotor flux estimation error only increase when observer working at zero speed region. (the performance of the observer with the Rs variation increased 50\% were not shown in [23]) 

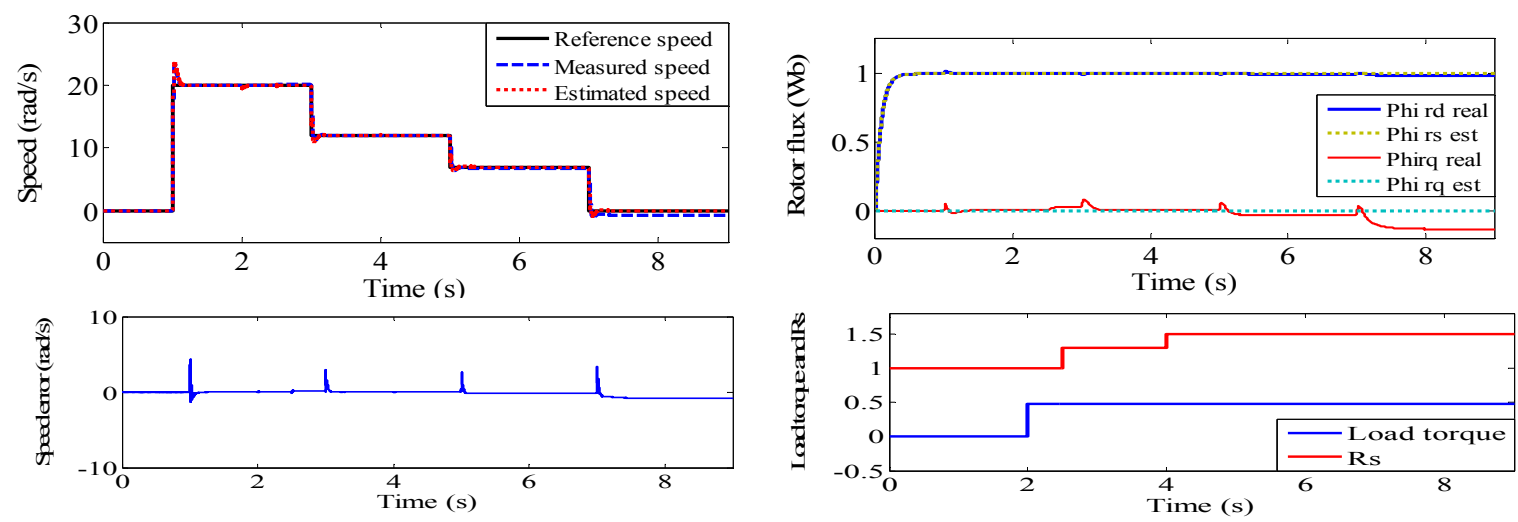

Fig. 8 The performance of the NNSM_SC_MRAS observer when Rr variations

(a) Estimated speed (b) Speed error (c) Estimated Rotor flux (d) Load torque

D. Load Perturbations and the regenerating mode operation

The robustness of the speed estimation of the observer to a sudden torque perturbation has been surveyed in this test. It was carried out to prove the behavior of the proposed scheme when load torque variations. Fig. 9a shows the speed estimation performance of NNSM SC MRAS observer and drive system with the rotor speed responses of the proposed MRAS observer to a variation in load torque and rotor speed for the motoring regions of operation to a speed demand of $20 \mathrm{rad} / \mathrm{s}$ increase to $80 \mathrm{rad} / \mathrm{s}$, then reducing to $30 \mathrm{rad} / \mathrm{s}, 25 \%$ load applied at $3.5 \mathrm{~s}$, increasing to $75 \%$ load at $7.5 \mathrm{~s}$, and reducing to zero at $12 \mathrm{~s}$. Fig. 9b shows the regenerating operation regions, a speed demand of $-5 \mathrm{rad} / \mathrm{s}, 25$ $\mathrm{rad} / \mathrm{s}$ with $25 \%$ load and $55 \%$ load applied at $4 \mathrm{~s}, 7.5 \mathrm{~s}$ before a severe load torque reversal from $55 \%$ to $55 \%$ occurs at $8.75 \mathrm{~s}$. These result shows the proposed improved current MRAS scheme given better the transient and steady state performance than to the TMRAS in [24] (Fig.9; 10). This is due to the stator current based scheme is not directly affected by stator voltage, in contrast, TMRAS scheme in [24] for rotor flux estimation is affected by this voltage hence the proposed scheme have better performance
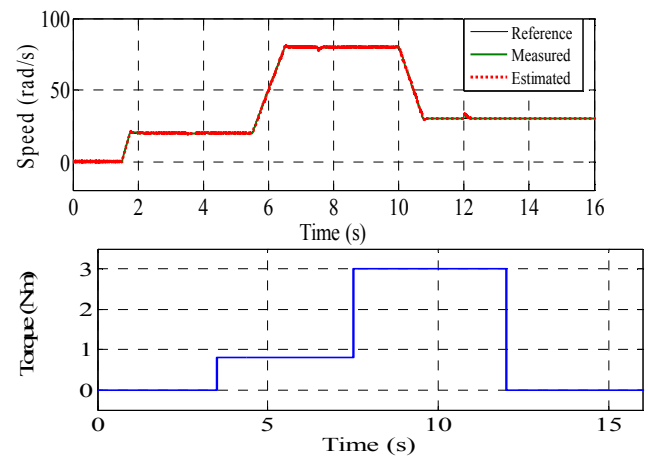

especially at low speed with less steady state error. In Fig 14 from result of the flux and current responses show the proposed schemes capability of handling regenerative operation and large load changes better [24].

The behavior of the proposed scheme with rotor speed was kept by zero during test, the speed estimation performance for load disturbance rejection at $+25 \%$ load in time $1.5 \mathrm{~s}-3 \mathrm{~s} ;-25 \%$ load in time $3 \mathrm{~s}-$ $4.5 \mathrm{~s}$; and $6 \mathrm{~s}-7.5 \mathrm{~s} ; 75 \%$ load in $9 \mathrm{~s}-10.5$. Fig. 15 show the reference, measured, and estimated speed, these results show that the speed responses of the drive using the proposed NN SC MRAS observer occurs immediately when the torque steps are given (Fig. 10). The small oscillations occur when $75 \%$ load rejected, however, very low estimation errors of the proposed observer, even during the speed transient that caused by the torque step, the estimated speed follows the real speed is very well. Comparing these result with the result in [24] (Fig. 12) is easily seen using SC_MRAS based observer with the improved rotor flux identify using SM given the performance better. in [24] speed and rotor flux estimation error increase high when applying load, on the contrary, the NNSM_SC_MRAS scheme operates very well in whole survey range.
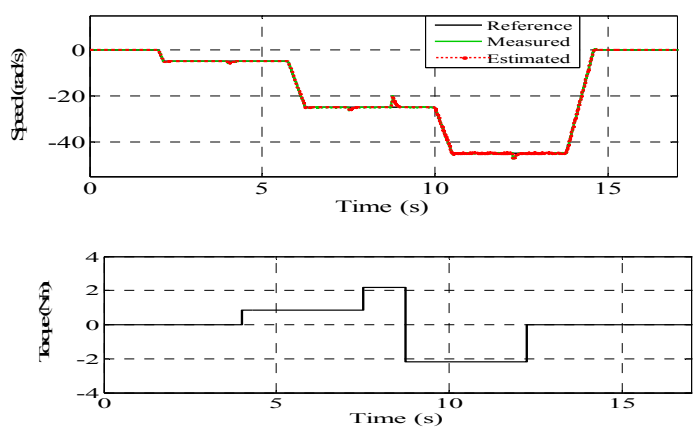

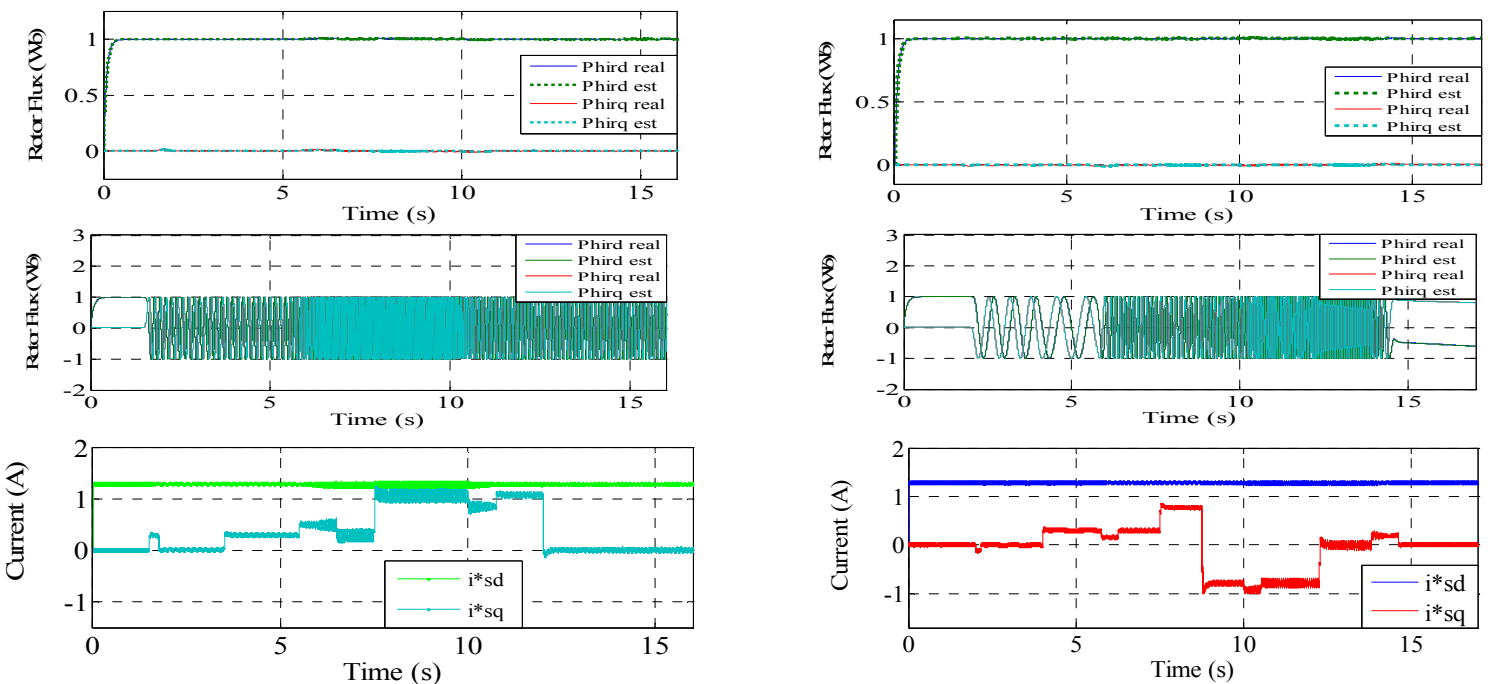

Fig. 9 Load Perturbations and the regenerating mode operation test:

(a.) the Simulated responses to variation in speed and load demands for motoring operation; (b) Simulated responses to variation in negative speed and load demands for both motoring and regenerative operation.
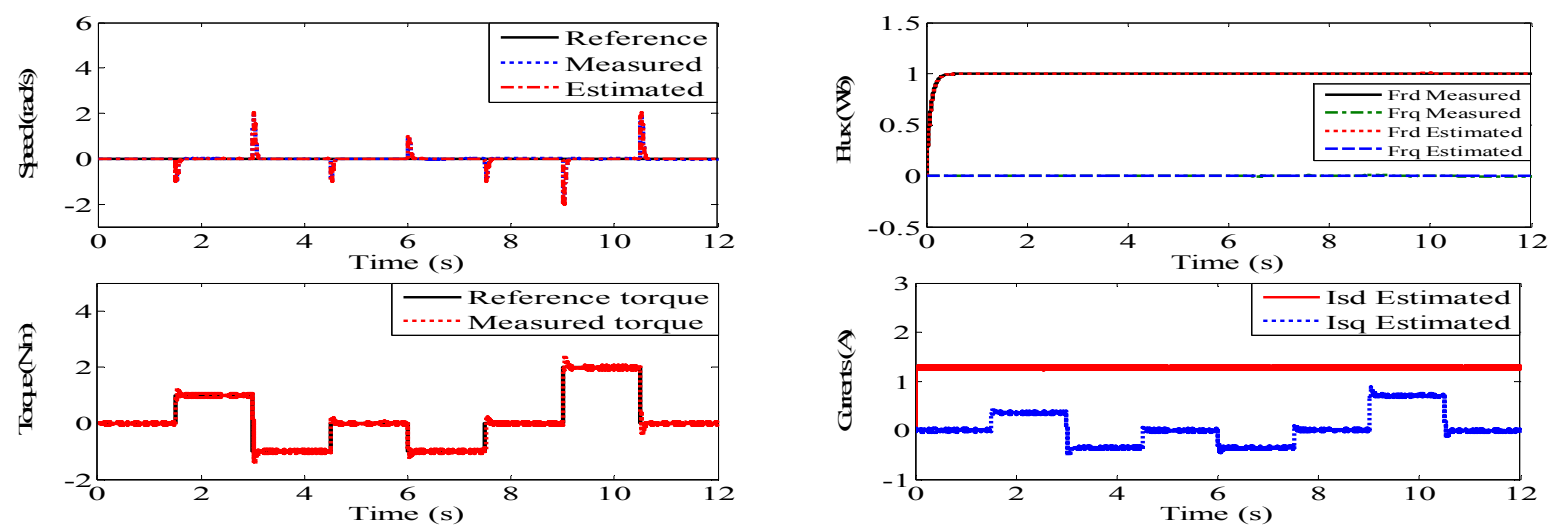

Fig. 1. Load Perturbations test at zero speed, load torque various 


\section{CONCLUSION}

This paper has presented a NNSM_SC_MRAS speed observer for high performance SPIM drives using NN and SM. It lead evoluting and improving the MRAS observer shown in [26]. The new SC_MRAS speed observer using the TLS algorithm instead of OLS algorithm [27], BPN algorithm [35] to can both reducing the computation effort and still improving the performance of proposed observer. In addition, the adaptive model based on $\mathrm{NN}$ is implement in prediction mode also increase accuracy and stability both in transient and stable state operations. Especially, in this proposed observer, the rotor flux is identified based on adaptive SM technique. The improvement of Rotor Flux Estimation for SC MRAS-Based Sensorless SPIM drives help to eliminate the disadvantages in SC MRAS based observer such as stator resistance sensitivity, and flux open loop integration which may cause dc drift and initial condition problems or instability in the regenerating

\section{References.}

[1] E. Levi, Multiphase electric machines for variablespeed applications, IEEE Transactions on Industrial Electronics. 2008, 55(5), $1893-1909$

[2] [R. Kianinezhad, B. Nahid-Mobarakeh, L. Baghli, F. Betin, G.A. Capolino, Modeling and Control of Six-Phase Symmetrical Induction Machine Under Fault Condition Due to Open Phases, IEEE Trans. Ind. Elec., 2008,55 (5), 1966-1977.

[3] Kubota, H., Matsuse, K., Nakano, DSP-based speed adaptive flux observer of induction motor, IEEE Trans. Ind. Appl., 1993, 29, (2), 344-348.

[4] S. Yin, S. X. Ding, X. C. Xie and H. Luo, A Review on Basic Data Driven Approaches for Industrial Process Monitoring, IEEE Trans. Ind. Electron., 2014, 61(11), 6418-6428.

[5] S. Hussain, M.A. Bazaz, Neural network observer design for sensorless control of induction motor drive, IFAC-Papers OnLine, 2016, 49, 106-111.

[6] Vieira R., Gastaldini C, Azzolin R, Gründling. Discrete-time sliding mode speed observer for sensorless control of induction motor drives. IET Electr. Power Appl., 2012, 6, (9), 681-688.

[7] Jafarzadeh S, Lascu C, Fadali. State estimation of induction motor drives using the unscented Kalman filter. IEEE Trans. Ind. Electron. 2012, 59(11), 4207-4216.

[8] Schauder. Adaptive speed identification for vector control of induction motors without rotational transducers. IEEE Trans. Ind. Appl. 1992, 28 (5), 1054-1061.

[9] RaviTeja AV, Chakraborty C, Maiti S, Hori. A new model reference adaptive controller for four quadrant vector controlled induction motor drives. IEEE Trans. Ind. Electron. 2012, 59, (10), 37573767

[10] Maiti S. Verma V, Chakraborty C. Hori. An adaptive speed sensorless induction motor drive with artificial neural network for stability mode of operation, therefore, enhancing the rotor flux estimation, speed estimation and control accuracy at very low and zero stator frequency operation help improve the overall observer and drive system performance.

The theoretical analysis is validated by simulation tests of the sensorless SPIM drive system under different operating conditions and these simulation results are given to compare the performance of the proposed observer with recent proposed observer [23, 24, 32, 33, 34]. The comparison data have proven that the proposed NN SM SC MRAS observer are quicker convergence in speed estimation, better dynamic performances; lower estimation errors both in transient and steady-state operation. The terms of accuracy of the NN SM SC MRAS observers is quite high and it is robustness against motor parameter variations, especially at low and zero speed region.

enhancement. IEEE Trans. Ind. Inf. 2012, 8, (4), 757-766

[11] Yaman B, Zbede, Shady MG, and David J, Atkinson. Model Predictive MRAS Estimator for Sensorless Induction Motor Drives. IEEE Trans. Ind. Electronics. 2016, 63 (6), 3511 - 3521.

[12] Abdelhak B, Bachir B. A High Gain Observer Based Sensorless Nonlinear Control of Induction Machine. International Journal of Power Electronics and Drive System (IJPEDS). 2015, 5(3), 305-314.

[13] Flah A, Sbita L. An adaptive high speed PMSM control for electric vehicle application. Journal of Electrical Engineering. 2012, 12(3),165-177.

[14] Foo G, Rahman. Sensorless sliding-mode MTPA control of an IPM synchronous motor drive using a sliding-mode observer and $\mathrm{HF}$ signal injection. IEEE Trans. Ind. Electron. 2010, 57(4), 1270-1278.

[15] Flah A, Novak M, Lassaad S. An Improved Reactive Power MRAS Speed Estimator With Optimization for a Hybrid Electric Vehicles Application. J. Dyn. Syst. Meas. Control. 2018,140(6), 061016.

[16] Holtz. Sensorless control of induction motor drives. Proc. of the IEEE. 2002, 90(8), 1359-1394.

[17] Flah A, Sbita L, Mouna BH. Online MRAS-PSO PMSM parameters estimation," International Review on Modelling and Simulations, 2011, 4(3), 980-987.

[18] H oltz J and Quan J. Drift and parameter compensated flux estimator for persistent zero stator frequency operation of sensorless controlled induction motors. IEEE Trans. Ind. Appl., 2003, 39(4), 1052-1060.

[19] Regaya C.B, Farhani F, Zaafouri A. Chaari A, A novel adaptive control method for induction motor based on Backstepping approach using dSpace DS 1104 control board, Mechanical Systems and Signal Processing. 2018, 100, 466-481.

[20] Horch M, Boumediene A, Baghli L. MRAS-based Sensorless Speed Integral Backstepping Control for 
Induction Machine, using a Flux Backstepping Observer. International Journal of Power Electronics and Drive System (IJPEDS)., 2017, 8(4), 1650-1662.

[21] Jannati M, Idris NRN, Aziz MJA. Indirect Rotor Field-Oriented Control of Fault-Tolerant Drive System for Three-Phase Induction Motor with Rotor Resistance Estimation Using EKF. TELKOMNIKA Indonesian Journal of Electrical Engineering. 2014, 12(9), $6633-6643$

[22] Jannati M, Asgari SH, Idris NRN, Aziz MJA. Speed Sensorless Direct Rotor Field-Oriented Control of Single Phase Induction Motor Using Extended Kalman Filter. International Journal of Power Electronics and Drive System (IJPEDS). 2014, 4(4), 430-438.

[23] Benlaloui I, Drid D, Alaoui LC, Ouriagli M. Implementation of a New MRAS Speed Sensorless Vector Control of Induction Machine. IEEE Transactions on Energy Conversion. 2015, 30(2), $588-595$.

[24] Smith AN, Shady MG, Finch JW. Improved Rotor Flux Estimation at Low Speeds for Torque MRASBased Sensorless Induction Motor Drives. IEEE Transactions On Energy Conversion, 2016, 31(1), $270-282$

[25] Ngoc TP, Diep PN, Khuong HN, Nho VN. An Improved Neural Network SC MRAS Speed Observer in Sensorless, WSEAS TRANSACTIONS on SYSTEMS and CONTROL,13, Art. \#39, , 2018, 364-374.

[26] Shady MG, Giaouris D, and Finch JW. Stator current model reference adaptive systems speed estimator for regenerating-mode low-speed operation of sensorless induction motor drives. IET Electr. Power Appl., 2013, 7(7), 597-606.

[27] Kowalska TO, Dybkowski M. Stator-Current-Based MRAS Estimator for a Wide Range SpeedSensorless Induction-Motor Drive. IEEE Transactions On Industrial Electronics, 2010, 57(4), 1296-1308.

[28] Yazdanpanah R, Soltani J, Markadeh GR Arab. Nonlinear torque and stator flux controller for induction motor drive based on adaptive inputoutput feedback linearization and sliding mode control. Energy Convers Manag 2008;49(4):541-50.

[29] Matheus J. H and Fink K. D. Numerical Methods Using Matlab. 4th ed. Upper Saddle River, NJ: Prentice-Hall, 2004.

[30] Cirrincione G, Cirrincione M, Hérault J, Van Huffel $\mathrm{S}$. The MCA EXIN neuron for the minor component analysis: Fundamentals and comparisons. IEEE Trans. Neural Netw., 2002, 13(1), pp. 160-187.

[31] Kubota H, Matsuse K, Nakano T. DSP-Based Speed Adaptive Flux Observer of Induction Motor. IEEE Trans. Ind. Appl., 1993, 29(2), 344-348.

[32] Abhisek P, Sukanta D Ajit K. Chattopadhyay. An Improved Rotor Flux Space Vector Based MRAS for Field Oriented Control of Induction Motor
Drives., IEEE Transactions on Power Electronics. 2018, 33(6), 5131 - 5141

[33] Tarchała G, Orłowska K.T. Equivalent-Signal Based Sliding Mode Speed MRAS-type Estimator for Induction Motor Drive Stable in the Regenerating. IEEE Trans. Ind. Electron. 2018, 65(9), 6936 - 6947

[34] Horch M, Abdelmadjid B, Lotfi B. MRAS-based Sensorless Speed Integral Backstepping Control for Induction Machine, using a Flux Backstepping Observer., International Journal of Power Electronics and Drive System (IJPEDS)., 2017, 8(4), 1650-1662

[35] Ngoc TP, Diep PN, Khuong HN, Nho VN. New Version of Adaptive Speed Observer based on Neural Network for SPIM, Intelligent Networks and Systems Society, 2018, 11(6), 95-107 . 